\title{
Hubungan Senam Hamil dengan Nyeri Punggung Pada Ibu Hamil Trimester III
}

\author{
Relationship Between Pregnancy Exercises and Low Back Pain Issue For \\ Pregnant Women at Their Third Quarter Period of Pregnancy
}

\section{Miratu Megasari}

\section{Prodi Ilmu Kebidanan STIKes Hang Tuah Pekanbaru}

\begin{abstract}
ABSTRAK
Salah satu ketidaknyamanan yang sering timbul pada kehamilan adalah nyeri punggung. Nyeri punggung merupakan gangguan yang banyak dialami oleh ibu hamil sepanjang masa-masa kehamilan hingga periode pasca natal. Salah satu upaya yang bisa dilakukan untuk mengurangi nyeri punggung selama kehamilan adalah dengan melakukan senam hamil. Penelitian ini bertujuan untuk mengetahuai Hubungan Senam Hamil Terhadap Nyeri Punggung Pada Ibu Hamil Trimester III Di RB Fatmawati. Jenis penelitian adalah analitik kuantitatif. Lokasi penelitian dilaksanakan di RB Fatmawati pada tanggal 28 Febuari-31 Maret 2015. Populasi dalam penelitian ini sebanyak 89 orang dengan sampel sebanyak 47 orang ibu hamil dengan tekhnik Acciddental sampling. Data yang digunakan dalam penelitian ini adalah data primer yang dianalisa menggunakan uji statistik chi square. Diperoleh $\mathrm{p}$ value $=0,000$, dimana $p$ value lebih kecil dari $\alpha(0,05)$, hal ini menunjukkan bahwa ada hubungan yang signifikan antara senam hamil terhadap nyeri punggung di RB Fatmawati tahun 2015. Dari uji statistik juga diperoleh nilai OR (Odds Ratio) $=2,600$ artinya ibu yang tidak melakukan senam hamil 2.6 kali lebih tinggi berisiko mengalami nyeri punggung dari pada ibu yang melakukan senam hamil. Kesimpulan senam hamil bisa mengurangi nyeri punggung.
\end{abstract}

Kata Kunci: Senam Hamil, Nyeri Punggung.

\section{ABSTRACT}

Low back pain is one of the discomfort which often occurred during pregnancy. Lowback pain is a condition experienced by many pregnant women throughout pregnancy period to the post-delivery period. One of the solutions to address this issue is by doing exercise for pregnancy women. The study was conducted to find out the effect of pregnancy exercisesto reduce low back pain issue. The data source is pregnant women on their third quarter of pregnancy period in Fatmawati's private clinic during 28th February 2015 until 31 March 2015. This is aquantitative analysis study. The number of samples are 89 pregnant women and 47 out of them are choosen by accidental sampling technique. Primary data in this study has been analyzed using chi square statistical test. The result of this study showed that $p$ value $=0.000$; which is $p$ value which is smaller than $\alpha(0.05)$. It indicated that there is a significant effect of pregnancy exercises to reduce low back pain issue. Statistical test result showed that the OR (Odds Ratio) value $=2.600$, which mean that pregnant women who did not take pregnancy exercises have likelihood to suffer from low back pain 3 times higher than pregnant women who took it. In brief, it can be seen that pregnancy exercise can be a solution to solve the low back pain issue during pregnancy period.

Key words: pregnancy exercise, low back pain

\section{PENDAHULUAN}

Nyeri pungung saat kehamilan mencapai puncak pada minggu ke-24 sampai dengan minggu ke28 , tepat sebelum pertumbuhan abdomen mencapai titik maksimum, selain itu menurut hasil penelitian epidemiologi yang terbatas yang dilakukan oleh Mayer yang dikutip oleh Yosefa, Febriana ea all (2014) nyeri punggung sering di perparah dengan terjadinya backache atau sering disebut dengan "nyeri pungung yang lama". Backache ini ditemukan pada
$45 \%$ wanita saat dicatat kehamilannya, meningkat $69 \%$ pada minggu ke-28 dan hampir bertahan pada tingkat tersebut. Keluhan nyeri punggung yang dialami oleh ibu hamil tentunya tidak bisa dibiarkan begitu saja. Menurut Yuliarti dan Nurheti (2010) Salah satu cara untuk meningkatkan kesehatan selama kehamilan adalah dengan melakukan olah raga ringan seperti senam hamil. Senam hamil adalah terapi latihan gerak untuk mempersiapkan ibu hamil, secara fisik atau mental, pada persalinan cepat, aman dan spontan.

\footnotetext{
${ }^{1}$ Alamat Korespodensi: Miratu Megasari, J1. Durian Ujung Gg Al-Manar No 103e, Email: ratubaik@gmail.com
} 
Ibu hamil dianjurkan untuk mengikuti senam hamil bila kandungan sudah mencapai usia 6 bulan (Asrinah, 2010). Menurut Agnesia (2010) Jenis olah tubuh yang paling sesuai untuk ibu hamil adalah senam hamil, disesuaikan dengan banyaknya perubahan fisik seperti pada organ genital, bagian perut kian membesar, dan lain-lainnya. Sebaiknya ibu hamil mempersiapkan segala hal yang bisa membantu selama masa hamil serta saat proses melahirkan, salah satunya adalah dengan melakukan senam hamil. Mengikuti senam hamil secara teratur dan intensif, maka ibu hamil dapat menjaga kesehatan tubuh dan janin yang dikandung secara optimal (Widianti dan Proverawati, 2010).

Senam hamil adalah suatu bentuk latihan guna memperkuat dan mempertahankan elastisitas otot-otot dinding perut, ligamenligamen, serta otot dasar panggul yang berhubungan dengan proses persalinan. Latihan ini berfungsi untuk memperkuat stabilitas inti tubuh yang akan membantu memelihara kesehatan tulang belakang. Mempunyai kekuatan tubuh yang baik dapat meningkatkan keseimbangan dan kestabilan individu serta meminimalkan risiko trauma tulang belakang ataupun jatuh pada saat hamil. Senam hamil dapat meringankan keluhan nyeri punggung yang dirasakan oleh ibu hamil karena didalam senam hamil terdapat gerakan yang dapat memperkuat otot abdomen ( Yosefa, et all, 2013).

Sejalan dengan penelitian Yosefa, et all, Hasil penelitian menunjukkan bahwa karakteristik responden paling banyak berusia 20-35 tahun (83,3\%), multigravida $(83,3 \%)$, beradapada trimester $2(53,3 \%)$, iburumahtangga (90\%), tingkat pendidikan menengah $(86,7 \%)$, Pemberian senam hamil pada kelompok eksperimen menurunkan intensitas nyeri punggung pada ibu hamil dengan selisih nilai rata-rata intensitas nyeri sebesar 2,40 dan berdasarkan hasil uji wilcoxon menunjukkan signifikansi dengan nilai $\mathrm{p}(0,000)<\alpha$ $(0,05)$. Pada kelompok control terjadi penurunan intensitas nyeri namun tidak signifikan dengan selisih rata-rata intensitas nyeri sebesar 0,47 dan berdasarkan hasil uji wilcoxon menunjukkan tidak signifikan dengan nilai $p(0,159)>\alpha(0,05)$. Hasil uji $t$ independent dimana diperoleh $\mathrm{p}(0,001)<\alpha(0,05)$. Hal ini berarti terdapat perbedaan yang signifikan antara rata-rata intensitas nyeri punggung ibu hamil pada kelompok eksperimen dan kelompok control sesudah diberikan senam hamil, dengan demikian dapat disimpulkan bahwa senam hamil efektif terhadap penurunan nyeri punggung pada ibu hamil.

Nyeri punggung lazim terjadi pada kehamilan dengan insiden yang dilaporkan bervariasi dari kirakira 50\% di Inggris dan Skandivia sampai mendekati $70 \%$ di Australia. Mantle melaporkan bahwa 16\% wanita yang diteliti mengeluh nyeri punggung hebat dan 36\% dalam kajian Ostgaard et al Tahun 1991 (Lichayati dan Kartikasari, 2013). Sejalan dengan penelitian yang dilakukan oleh Lichayati dan
Kartikasari, tentang Hubungan senam hamil dengan nyeri punggung pada ibu hamil di polindes desa lanak kecamatan kedungpring Kabupaten lamongan tahun 2013, hasil penelitiannya menunjukkan bahwa lebih dari sebagian $(75 \%)$ ibu hamil yang tidak pernah melakukan senam hamil mengalami nyeri punggung dan seluruh (100\%) ibu hamil yang sering melakukan senam hamil tidak mengalami nyeri punggung. Hasil pengujian statistic diperoleh nilai $\mathrm{r}=0,544$ dan $p=$ $0,001(p<0,05)$ artinya terdapat hubungan yang signifikan antara senam hamil dengan nyeri punggung. Dengan demikian ibu hamil yang melakukan senam hamil secara teratur maka semakin kecil keyakinan mengalami keluhan nyeri punggung.

Berdasarkan survey awal yang dilakukan oleh peneliti di RB. Fatmawati didapatkan dari 10 orang ibu hamil yang mengalami nyeri punggung 7 diantaranya mengalami perubahan nyeri punggung setelah melakukan senam hamil. Dengan melihat permasalahan yang mempunyai kaitan satu dan lainya serta berdasarkan data yang didapat dari RB Fatmawati di atas dapat dilihat angka yang melakukan senam hamil pada trimester III dari tahun ketahun masih besar kasusnya. Berdasarkan latar belakang yang diuraikan tersebut penulis tertarik melakukan penelitian mengenai "Hubungan senam hamil dengan nyeri punggung pada trimester III di RB Fatmawati".

\section{METODE PENELITIAN}

Jenis penelitian analitik kuantitatif, dengan desain penelitian cross sectional (Notoatmodjo, 2005) yaitu untuk melihat hubungan senam hamil terhadap nyeri punggung. Penelitian ini dilakukan di RB Fatmawati dari tanggal 28 Februari-31 Maret 2015. Populasi dalam penelitian ini adalah ibu hamiltrimester III yang berkunjung diRB Fatmawati pada tahun 2014 sebanyak 89 orang. Sampel dalam penelitian ini adalah ibu hamil trimester III yang berkunjung di RB Fatmawati sebanyak 47 orang yang diambil menggunakan tekhnik pengambil sampel accidental sampling. Analisis data yang digunakan pada penelitian ini adalah analisa bivariat yang nantinya diuji dengan uji chi-square (Notoatmodjo. 2005)

\section{HASIL PENELITIAN}

\section{Analisis Univariat}

Analisis univariat dimaksudkan untuk mendeskripsikan dari masing-masing variabel yaitu variabel bebas dan variabel terikat dengan menggunakan tabel distribusi frekuensi. Berdasarkan hasil yang didapatkan akan dijadikan sebagai pembahasan. Hasil analisis univariat terlihat dari tabel 1 sebagai berikut: 
Tabel 1

Hasil Analisis Univariat

\begin{tabular}{lcc}
\hline \multicolumn{1}{c}{ Variabel } & N & \% \\
\hline Usia Kehamilan & & \\
28 Minggu & 8 & $17,0 \%$ \\
29 Minggu & 10 & $21,3 \%$ \\
30 Minggu & 4 & $8,5 \%$ \\
31 Minggu & 2 & $4,3 \%$ \\
32 Minggu & 3 & $6,4 \%$ \\
33 Minggu & 3 & $6,4 \%$ \\
34 Minggu & 5 & $10,6 \%$ \\
35 Minggu & 2 & $4,3 \%$ \\
36 Minggu & 4 & $8,5 \%$ \\
37 Minggu & 4 & $8,5 \%$ \\
38 Minggu & 2 & $4,3 \%$ \\
Total & 47 & $100 \%$ \\
Senam Hamil & & \\
Iya & 21 & $44,7 \%$ \\
Tidak & 26 & $55,3 \%$ \\
Total & 47 & $100 \%$ \\
Nyeri Punggung & & \\
Iya & 16 & $34,0 \%$ \\
Tidak & 31 & $66,0 \%$ \\
Total & 47 & $100 \%$ \\
\hline
\end{tabular}

\section{Analisis Bivariat}

Dari tabel 2 didapatkan hasil dari 21 orang ibu yang melakukan senam hamil seluruh nya tidak mengalami nyeri punggung yaitu sebanyak 21 orang $(100 \%)$, sedangkan dari 26 orang ibu yang tidak melakukan senam hamil ada 16 orang (61,5\%) yangmengalami nyeri punggung. Dari uji statistik chi square, diperoleh $\mathrm{p}$ value $=0,000$, dimana $\mathrm{p}$ value lebih kecil dari $\alpha(0,05)$, hal ini menunjukkan bahwa ada hubungan yang signifikan antara senam hamil terhadap nyeri punggung di RB Fatmawati tahun 2015. Dari uji statistik juga diperoleh nilai OR (Odds Ratio) $=2,600$ artinya ibu yang tidak melakukan senam hamil 2.6 kali lebih tinggi berisiko mengalami nyeri punggung dari pada ibu yang melakukan senam hamil.

Tabel 2

Analisis Bivariat

Hubungan Senam Hamil terhadap Nyeri Punggung

\begin{tabular}{ccccccc}
\hline No & Senam & \multicolumn{2}{c}{ Nyeri Punggung } & Total & Nilai & OR \\
\cline { 3 - 4 } & Hamil & Iya & Tidak & & P & \\
\hline 1 & Iya & 0 & 21 & 21 & 0,000 & 2,600 \\
& & $(0,0 \%)$ & $(100 \%)$ & $(100 \%)$ & & \\
\cline { 1 - 4 } 2 & Tidak & 16 & 10 & 26 & & \\
& & $(61,5 \%)$ & $(38,5 \%)$ & $(100 \%)$ & & \\
\cline { 1 - 4 } & Total & 16 & 31 & 47 & & \\
& & $(34,0 \%)$ & $(66,0 \%)$ & $(100 \%)$ & & \\
\hline
\end{tabular}

\section{PEMBAHASAN}

Dari hasil penelitian hubungansenam hamil terhadap nyeri punggung di RB Fatmawati tahun 2015.
Dari tabel 4 diatas didapatkan hasil dari 21 orang ibu yang melakukan senam hamil seluruhnya tidak mengalami nyeri punggung yaitu sebanyak 21 orang (100\%), sedangkan dari 26 orang ibu yang tidak melakukan senam hamil ada 16 orang $(61,5 \%)$ yang mengalami nyeri punggung, dengan $\mathrm{P}$ value $=0,000(\mathrm{P}$ $<0,05$ ), artinya ada hubungan yang signifikan antara senam hamil dengan nyeri punggung pada ibu hamil trimester III di RB Fatmawati.

Salah satu ketidaknyamanan yang sering timbul adalah nyeri punggung. Nyeri punggung merupakan gangguan yang banyak dialami oleh ibu hamil yang tidak hanya terjadi pada trimester tertentu, tetapi dapat dialami sepanjang masa-masa kehamilan hingga periode postnatal. Wanita yang pernah mengalami nyeri punggung sebelum kehamilan beresiko tinggi mengalami hal yang sama ketika hamil, oleh karena itu penting sekali untuk dapat membedakan nyeri punggung yang terjadi penyebab lain (Lichayati,2013).

Menurut penelitian dari Yosepa, et all (2013) nyeri pungung mencapai puncak pada minggu ke-24 sampai dengan minggu ke-28, tepat sebelum pertumbuhan abdomen mencapai titik maksimum. Menurut hasil penelitian epidemiologi yang terbatas yang dilakukan oleh Mayer, dkk (1994 dalam Mander, 2014) nyeri punggung sering di perparah dengan terjadinya backache atau sering disebut dengan "nyeri pungung yang lama". Backache ini ditemukan pada $45 \%$ wanita saat dicatat kehamilannya, meningkat $69 \%$ pada minggu ke-28 dan hampir bertahan pada tingkat tersebut. Salah satu cara untuk meningkatkan kesehatan selama kehamilan adalah dengan melakukan olah raga ringan seperti senam hamil. Senam hamil adalah suatu bentuk latihan guna memperkuat dan mempertahankan elastisitas otot-otot dinding perut, ligament-ligamen, serta otot dasar panggul yang berhubungan dengan proses persalinan. Senam hamil dapat meringankan keluhan nyeri punggung yang dirasakan oleh ibu hamil karena didalam senam hamil terdapat gerakan yang dapat memperkuat otot abdomen (Yosefa, et all, 2013).

Senam dapat mengurangi berbagai gangguan umumnya terjadi selama masa kehamilan seperti pemekaran pembuluh darah (Varises), sakit pinggang serta nyeri otot dan persendian: meningkatkan stamina, yang sangat diperlukan selam persalinan, dan menguatkan serta mengencangkan otot-otot yang paling banyak dipengaruhi oleh kehamilan: otot pelvis, otot perut dan otot pinggang. Program senam hamil yang baik juga dapat memperbaiki postur tubuh, karena pengaruh rahim dan perut yang mengembang sehingga menyebabkan daerah pelvis bergeser kedepan. Gerakan-gerkan senam untuk mengencangkan otot-otot pantat, punggung, bahu dan perut. Hasil penelitian (1989) yang dimuat dalam American Journal of Obstetrics and Gynecology yang 
menunjukkan bahwa ibu-ibu yang melakukan kegiatan senam cukup sering dan teratur selama masa tiga bulan (Trimester terakhir), (Hanton, 2001).

Penelitian yang dilakukan oleh Lichayati (2013) tentang Hubungan senam hamil dengan nyeri punggung pada ibu hamil di polindes desa tlanak kecamatan kedungpring Kabupaten lamongan, hasil penelitiannya menunjukkan bahwa lebih dari sebagian (75\%) ibu hamil yang tidak pernah melakukan senam hamil mengalami nyeri punggung dan seluruh (100\%) ibu hamil yang sering melakukan senam hamil tidak mengalami nyeri punggung. Hasil pengujian statistik $p$ $=0,001(p<0,05)$ artinya terdapat hubungan yang signifikan antara senam hamil dengan nyeri punggung. Dengan diperoleh nilai $r=0,544$ artinya ibu hamil yang melakukan senam hamil secara teratur maka semakin kecil keyakinan mengalami keluhan nyeri punggung.

Menurut Asumsi peneliti berdasarkan hasil penelitian dan teori terkait, senam hamil mempunyai hubungan dengan nyeri punggung, dalam melakukan senam hamil tersebut otot-otot dinding abdomen, ligamen dan otot dasar panggul dapat terlatih semakin elastis lagi dan tidak mengalami kaku pada otot serta memberikan efek relaksasi bagi ibu, dengan semakin seringnya ibu melakukan senam hamil ini maka elastisitas otot semakin baik, sehingga dapat mengurangi rasa nyeri pada punggung ibu.

\section{KESIMPULAN}

Dari 47 responden, mayoritas responden yang berkunjung di RB Fatmawati yaitu dengan usia kehamilan 29 Minggu sebanyak 10 Orang (21,3\%), golongan umur 20-30 tahun sebanyak 34 Orang (72,3\%), yang melakukan senam hamil sebanyak 21 orang $(44,7 \%)$, dan yang mengalami nyeri punggung sebanyak 31 orang $(66,0 \%)$. Berdasarkan analisis bivariat terdapat hubngan antara senam hamil terhadap nyeri punggung dengan nilai $p$ value $=0,000$ dan nilai $\mathrm{OR}=2,600$.

\section{SARAN}

Bagi RB Fatmawati sebagai fasilitas kesehatan, diharapkan dapat lebih aktif dan selektif lagi terhadap penanganan maupun pencegahan keluhan nyeri punggung seperti meningkatkan konseling antara petugas kesehatan dan pasien, memberikan penyuluhan-penyuluhan, atau pun melalui pendekatan - pendekatan terutama di bidang kesehatan ibu dan lebih menggalakan lagi program senam hamil. Selain itu, Penyuluhan tentang senam hamil sebaiknya dilakukan secara berkala dengan memanfaatkan berbagai jalur komunikasi yang ada. Bagi peneliti lain, penelitian ini dapat berkesinambungan sehingga dapat dijadikan sebagai dasar untuk melanjutkan penelitian yang lebih mendalam, dengan lebih memperhatikan faktor-faktor lain yang memiliki pengaruh terhadap kejadian nyeri punggung. Bagi institusi pendidikan STIKes Hang Tuah, pentingnya penelitian tentang nyeri punggung agar diketahui cara penanggulangan dan mengetahui berbagai manfaat dari senam hamil itu sendiri, sehingga dapat dijadikan sebagai bahan perbandingan untuk penelitian yang lain dan menambah ilmu pengetahuan terhadap mahasiswa STIKes. Oleh karena itu penelitian seperti ini harus lebih banyak dilakukan dan dengan menggunakan metodologi penelitian yang dapat meminimalisir keterbatasan.

\section{UCAPAN TERIMAKASIH}

Kepada pihak RB Fatmawati yang telah memberikan kesempatan kepada penelliti untuk melaksanakan penelitian, dan kepada seluruh tim yang telah membantu sehingga terlaksananya penelitian ini.

\section{DAFTAR PUSTAKA}

Asrinah.(2010). AsuhanKebidananMasaKehamilan. Yogyakarta: GrahaIlmu.

Agnesia, Renviliadanlinggarjati, Hendrik.(2012). 30 MenitPanduanSenamHamil Di RumahAnda. Yogyakarta: Medpress.

Hanton W, Thomas. (2001). Panduan Senam Kebugaran Untuk Wanita Hamil.Jakarta: Raja Grafindo Persada.

Kartikasari Indah, RatihdanLichayatiUl', Isma. (2013). HubunganSenamHamilDenganNyeriPunggungP adalbuHamil

$D i$ PolindesDesaTlanakKecamatanKedungpringKa bupatenLamongan.Jurnalsurya,Vol. 01， No. XIV,April 2013. Di perolehdarihttp://stikesmuhla.ac.id/v2/wpontent/uploads/jurnalsurya/noXIV/10.pdf AksesTanggal 05 Januari.

Notoatmodjo, Soekdjo. (2005). MetodologiPenelitianKesehatan. Jakarta: RinekaCipta.

Widianti Tri, AnggriyanadanProverawati, Atikah. (2010). SenamKesehatan. Yogyakarta: MuhaMedika.

Yuliarti, Nurheti. (2010). Wanita Hamil Dan Menyusui. Yogyakarta: Andi Offset.

Yosefa, Febriana ea all. (2013).Efektifitas Senam Hamil Terhadap Penurunan Nyeri Punggung Pada Ibu Hamil Jurnal Online Keperawatan, Vol 1,No 1 (2014),http://jom.unri.ac.id/index.php/JOMSIK/ articele/view/3537/3432(Di Akses Tanggal 01 Febuary 2015). 